\title{
Service quality of Early Childhood Education web portals in Finnish municipalities
}

\author{
Eija Koskivaara ${ }^{\mathrm{I}}$ and Päivi Pihlaja ${ }^{2}$ \\ 1 Turku School of Economics, Information System Science, \\ Rehtorinpellonkatu 3, 20500 Turku, Finland, eija.koskivaara@tse.fi, \\ WWW home page: $h t t p: / / w w w . t s e . f i / t j t$ \\ 2 University of Turku, Faculty of Education, Assistentinkatu 5, FI- \\ 20014 Turku, ppihlaja@utu.fi, \\ WWW home page: http://www.utu.fi
}

\begin{abstract}
Increasing number of governmental organizations have transformed material on their web sites as a way of providing users with information about their products and services. In this paper, we apply Yang et al (2005) instrument for analyzing municipal early childhood education (ECE) web sites in Finland. The objective of the study was to find out the quality of ECE web portals as well as to give hints to improve their value from users' point of view. In general the five dimensions, usability, usefulness of content, adequacy of information, accessibility, and interaction, of the Yang et al model seems to be applicable also in the early childhood education environment.
\end{abstract}

\section{Introduction}

Increasing number of governmental organizations have set up material on their web sites as a way of providing users with information about their products and services. In this paper we are interesting of the quality of the early childhood education (ECE) information and service at the web sites, and what is the situation of the transformation of this information and service into virtual mode in Finland. The ECE in Finland is the state and municipality controlled public service, which every child have subjective right to have. The main objective of ECE in day care is to promote child's healthy growth, development and learning skills. The social task of ECE includes the promotion of child's social, intellectual and emotional development [2].

Please use the following format when citing this chapter:

Koskivaara, F., Pihlaja, P., 2007, in IFIP International Federation for Information Processing, Volume 252, Integration and Innovation Orient to E-Socicty Volume 2, eds. Wang, W., (Boston: Springer), pp. 382-389. 
Day care should also support parents in raising their children [1,2]. Parents are seen more and more as partners. State is guiding municipalities by resources and information and for example the government determines the maximum price per month, which means that there is no price elasticity of the ECE service. According to Lee, Tan \& Trimi [5], the value and quality of public services for citizens are essential of the e-governmental services. The rewards of virtual government-tocitizen $(\mathrm{G} 2 \mathrm{C})$ services are realized partially through well-design web sites, since nowadays they act as the primary contact with customer. Surfing the municipal ECE web sites reveals that the functionality and especially the content varies a lot.

The research of service quality of web portals is still an under-defined construct and heavily depends on the type of site. For example, Lightner [6] has proposed a list of 50 functional requirements to create more effective business-to-customer (B2C) sites. However, these requirements do not directly fit into the governmental services, which have no price elasticity. Hassan and Lee [4] have evaluated political web sites with benchmarking approach. In this paper, we apply the instrument developed by Yang, Cai, Zhou, and Zhou [7] for ECE web sites in Finland. The main selection criteria are that its focus is also on non-commercial web sites, built up by non-profit organizations. This instrument measures user perceived service quality of information presenting web sites. The instrument focuses on usability, usefulness of content, adequacy of information, accessibility, and interaction of the web site.

The research design is presented in section 2 . The analysis of the ECE web sites is presented in the section 3 with the help of earlier mentioned five dimensions. Section 5 outlines our improvements proposals which are partly based on benchmarking and identifying the "best practices" of other municipalities' ECE web sites in Finland. Section 6 discusses the results against the measurement instrument and concludes the paper.

\section{Research Design}

The web sites and their texts are produced in socially organized ways [3]. Therefore, these sites are social productions, which are not transparent representations of organizations, or organizations values. This means, that it is very interesting to draw back "the curtain" and to examine the content of ECE web sites in Finnish municipalities. In order to do that, we are using content analyze to municipal ECE web sites.

Primary we analyze four different municipal ECE web sites. The municipals are Turku, Lieto, Salo, and Uusikaupunki. The number of children in the ECE service varies from 900 to 6000 in the municipalities. The biggest municipality has divided its' services in to ten services areas. These four municipalities were selected to our cases because they are taking part to a project which is aiming to developed ECE processes and services with the help of information technology. This study is a part of bigger ongoing research and development process. 


\section{Quality of ECE information}

\subsection{Usability}

According to Yang et al. [7] studies, usability most significantly influences users' service quality perceptions of the web sites. Therefore, web sites should design so that its intended users are able to locate the needed information without difficulty. Therefore, we may say that in human-computer interaction usability refers to the elegance and clarity of the interaction. The usability of the case municipality ECE web sites are analyzed based on the following items: place and organization of ECE services, readability of the information, search facilities.

ECE services in Turku can be founded from the main page under the family- and social service menu, where they are the first service in the menu. The ECE services are organized based on the content of service. The main ECE menu also has link for frequently asked questions. The ECE services in Lieto can be founded from the main page under the social services, where ECE services were the first service in the menu. The ECE services in Lieto are also based on the content. In Salo the ECE services can be found under the service directory, where social services are one item. Under the social services all the services are presented in alphabetical order, where children's day care is again one item. The ECE services are organized based on the content. The ECE services in Uusikaupunki can be founded from the main page under the social- and health service menu, where all the services are presented in alphabetical order and the ECE services is one item. The ECE services are organized based on the content of service.

Readability of the information in Turku is good, which means that there is not too much text on the page and titles give a brief idea about the content. In Lieto the municipal main menu remains all the time on the left side of the page, which makes finding, reading and understanding the ECE content a little bit confused. Also, the layout of the Lieto ECE page is restless. The size of the letters and block capitals differ in disorder which makes the reading uneasy. The amount of the text in Salo ECE pages is at the moderate level, but some subtitles could help the reader. The amount and layout of the information per pages in Uusikaupunki ECE pages differs, which makes the reading uneasy.

Search facilities in Turku are always located at right-left corner of the page. Searching with the word "day care" gives 900 hints. Search facilities in Lieto are also located at the right-left corner the page. Searching with the word "day care" gives 13 hints. Search facilities in Salo are also located at the right-left corner the page, but new searching engine spring open after the search, which confused a little bit. Searching with the word "day care" gives 16 hints. Search facilities in Uusikaupunki are also located at the right-left corner the page, but again new searching engine spring open. This new searching machine searches either from all the pages or proposes precise pages. The searching with word "day care" gave 31 hint links organized by alphabetical order. 


\subsection{Usefulness of content}

Usefulness of content refers to the relevant information to the customer and valuable tips on services, customized information presentation and up-to-date information. The relevant information is based on customers needs. Before parents are sending in an application for a day care place to their child, they have right to know what kind of day care services are available. The way how the text is taking parents' point of view in describing services and guiding parents what to choose is important. Furthermore, this means description about how does the ECE come true and how do children react to new context and how to ease child's adaptation process. Therefore, child-centered information is of a great value in ECE web sites. Therefore, this arise several question such as, is the text easily to approach, does it communicate or try to start a dialog with parents, and with whom co-operation is essential. The key words examining the content of web site text are: client centered information, useful information about different kind of day care, goals and implementation of ECE.

Children's point of view is not seen in these web sites. In Turku web sites are written in bureaucratic and organizational way. In Lieto and Uusikaupunki parents are seen more as partners: "We are about 150 day care professionals in Lieto. We want to offer the best we can, to ensure that your child should enjoy in Lieto".

The information about different kind of day care services is in superficial level in every municipal. Sides are not dealing with the differences of family day care, group family day care and day care centres. The strengths and weaknesses of these should be told to parents. Parents have right to know what kind of education the personal is implementing, what features are common to different kind of services.

Every municipal is dealing with preschool education little bit more and detailed. Finnish preschool is meant to children at 6 years old, only one year period before school start. Minister of Education is in charge of preschool education and Ministry of Social and Health of day care.

Goals of ECE are most explicit in sites of Uusikaupunki, even thought the web implementation is light.

\subsection{Adequacy of information}

Adequacy of information is related to completeness of information. The ECE web portals should provide information to facilitate families understanding of the whole content of the ECE services. Indeed, families need supplemental services, such as professional advice, club activity, social services, school system, research reports, and hyperlinks to relevant web sites. In here the most important items are: information about services to children and families organized by municipals and other providers such as non-profit or private organizations, sufficient information for potential and existing customers, and detailed contact information.

Every municipality has information about the structure of possible day care services: family day care and day care centers. In Turku there is also some information of other providers, very well about private providers, but worse about other activities for families (clubs etc). In Salo the content of day care services is quite informative: what does family day care means. But in Salo in web sites other 
providers are quite invisible. There is information about family center, but other organizations are not seen in these web sites. In Lieto the information about different day care systems are written in pedagogical way. "Our goal in Lieto is offer to families in our municipal different kind of day care services so, that families needs are taken care of. We want to offer different kind of day care places, and also offer to children who are taken care at their homes possibility to interact with other children in groups and get stimulating clubs". So in Lieto, we can see also the ground ideas of municipal ECE-services. There is not information of other providers in web sites, which can be seen as a shortage. But Lieto is offering clubs for children who are not in day care services, which are more than many other municipalities, can offer. In Uusikaupunki there is also two kind of information about possible day care services. Firstly, the information includes a description of the service content. Secondly, the information focuses on possible ways how families can organize their children's day care i.e. either in family day care or day care centers. Also in Uusikaupunki the emphasis is on children and families. "The aim of the day care is together with homes to contribute the growth of child's harmonious personality. Essential in the ECE is the interaction and educational partnership of parents, children, and day care personal."

Detailed content information is also important; it is some kind of visiting card of a person, who is in charge of this service. This is well taken care in Lieto, Salo, and Uusikaupunki. In Turku it is difficult for a client to know to whom to contact.

\subsection{Accessibility}

Accessibility of web site involves two aspects, namely availability and responsiveness. In this study we focus on easiness of web site access and speed of web page loading, which are also emphasized by Yang et al. [7]. In this analyze we count how many clicking a user needs from the municipal main page to find the ECE service and one day care center.

In Turku, user needs two clicking to open ECE service page, when the main page is the starting point. To find one day care center requires three more clicking. In Lieto, user needs two clicking to open ECE service page, when the main page is the starting point. To get contact information to a daycare center one more clicking is needed. In Uusikaupunki, user needs two clicking to open ECE service page, when the main page is the starting point. Also in Uusikaupunki one more clicking is needed to get contact information to a day care center. In Salo, user needs two clicking to open ECE service page, when the main page is the starting point. To find one day care center requires two more clicking.

The speed of loading of the ECE sites of Turku and Uusikaupunki are high, which means user view their content very quickly. With Lieto pages the user can see and sense the exchange of the pages. The uploading and exchange of some pages in Salo are slow, which means that it takes five to six seconds. However, this slowness is not valid in every loading. 


\subsection{Interaction}

Yang et al. [7] argue that, web sites should satisfy users' information need by two interaction aspects. Firstly, interaction between users and web sites are needed, especially the possibility for inquiries is must. Secondly, users seek guidance, suggestions, and testimonies from peer users. In this study we look for the interaction the ECE web portals provide for user in the case municipalities.

All the case municipalities provide contact information, which also includes email address. Also digital application for ECE services can be downloaded via the web site. Besides, Lieto provides health inquiry application and Salo provides income inquiry application digitally. But, at the moment all the applications have to return manually. Turku ECE site keeps lists of frequently asked question about payment policy as well as some useful ECE links. Uusikaupunki and Salo have a link for the local community of the Mannerheim League for Child Welfare. None of the case companies has any peer services for the families.

\section{Proposed Improvements for ECE portals}

The following improvement focuses on the criteria mentioned earlier and emphasizes the users' point of view. In the Finnish public sector there is an aim to serve citizen from one point, therefore to find all the services from one place is attempting. This is where web portals really have advantage compared to other ways of providing informing about the services. Whether this one point of service really works with web portals is still a question, however at least Salo and e.g. Kirkkonummi have try to it. The next question is how to name the service so that users easily find the ECE services. Turku gives a nice example by emphasizing family point of view whereas other municipals strictly stick to social- and health services, which gives a little bit wrong view of the ECE service. Some of the municipals, like Kaarina, only present the services by alphabetical order, which hides the holistic view of the service content. E.g. in Tampere users have the possibility to select whether they want to see the service supply by alphabetical or content based order. By providing different kinds of ways to find the service really help citizens who certainly have different abilities to find and understand the messages.

Readability of the information in the ECE web sites really differs, and very often the picture is very restless. Therefore, guidelines as well as some training for the web writing are urgently needed. It seems that every municipal have search facilities in their web portals, but the improvement is needed to categorize the finding in a meaningful manner. For instance, some business intelligence could be embedded into the search engines.

Families demand valuable, reliable, up-to-date information from ECE web sites. Therefore, a formal policy of content development and information selection should be set. The main finding in this sector is that families can read something about day care, but there is too little information of the implementation of ECE and no information of how to adjust a child to new environment and child group. In these sites the information to parents is in organizational level and it does not give any 
empowerment for families. These sites could strengthen parenthood; give information of children and their development and especially how to support this phase of childhood. Transitions practices have a great value to an individual child, this process can be also supportive in new situation like this. Now-a-days parents are quite alone with this upbringing task and in a new situation when they are having a child. Migration and decrease of children in families are processes that bring generations apart of each others. Cultural legacy of care and upbringing is not so obvious what it was in agricultural Finnish society.

Day care is a service to families in Finland. In many other countries there is ECE services meant mainly to children, despite parents are at home or at work. It can be said that the pedagogical and developmental needs of children was ignored, and employment, adult-cantered factors were the main reason why this system was developed in Finland in 1970's.. So we have a tradition that is emphasizing more adult centred values comparing this to child-centered values. These values are "written" to web sites by absence of this kind of information.

Every municipal has a task of organize day care that is based on the law. Information about this service that municipalities organize is coming true very clear. Service guidance is a task that every municipal should do, but at the moment it is not coming true very well. The information of all kind of services that families with small children should need is presented in way one can describe at random and partially. Web sites are quite new structures to inform and communicate, and municipal services are leaning on "old fashioned bureaucratic line organizations" which needs time to confront new demands of citizens and technology.

In "big" municipalities, like Turku is in Finland with 170000 inhabitants, the way how a possible client get information to whom can contact is have great value to every people. Now municipalities over 100000 inhabitants can be seen as a faceless and distant organizations. This should change, because organizer of these services should tempt new clients to communication and partnership. There should be a person who can answer to questions on municipal level and of course a person who knows the situation at day care provider level.

As long as the content of the ECE web sites is such that the interaction between families and day care provider is very minimal or it does not exist the accessibility is not the first factor of users' perceived quality. However, when the service is on the web customers expect them to be available at all the times; they also desire speedy log-on, access, and download of documents etc.

ECE service providers may increase the interaction by digitalization of ECE application procedures, which has been done, for instance, in Tampere and Espoo. The application procedure in Espoo differs from Tampere so that it requires identification of the parent before sending an e-application to the authorities. Also some day care centers such as Keinuhevonen in Orimattila already uses digital application procedures. So far, none of the services providers use digital forms for inquiring absence during summer, Christmas, or other holidays. This is astonishing because by integrating these procedures into the operational management systems of the municipals really could spare niche resources of ECE function and allocate them into promoting child's healthy growth, development, and learning skills. 


\section{Conclusions}

The present paper analyses the municipal ECE web sites with the help of instrument. Families demand valuable, reliable, up-to-date information from ECE web sites. Therefore, a formal policy of content development and information selection should be set.

ECE services and implementation of ECE processes need further examination in Finland. The content of web sites of ECE services, implementation and its meaning to children has many weaknesses. One reason for this is that early childhood education and day care has a tradition of conflicting views in our society. One point of view is underlining the education and learning of small children. The other has long roots to social welfare and legislation brings out that "social welfare means social services, social assistance, social allowance and related measures intended to promote and maintain the social security and functional ability of the individual, the family and the community" [8]. One solution to create quality to ECE in national level can be the transition of the whole service system to the Ministry of Education.

In Finland were economical depression in 1990 's, when the services to children and child-families were diminished. Personal have many years of hard work behind and to create new quality and new information systems need both resources and enthusiasm. Attitudes and knowledge are going hand by hand, and therefore the IS competence of day care personal needs also some improvement.

As users at the moment do not conduct any online transactions, we have kept the security issues beyond the research scope. However, as municipals diversify their digital content of ECE services, web sites need strict security policies and have to use advanced security technologies.

\section{References}

1.Day care act $36(1973)$.

2.Day care act $117(1983)$.

3.N. Denzin and Y.S. Lincoln, The Handbook of Qualitative Reserch.Thousand Oaks: Sage Publications, 2000.

4.S. Hassan and F. Li, "Evaluating the usability and content usefulness of web sites:a benchmarking approach, Journal of Electronic commerce in Organizations , 3(2005), 46-47.

5. S.M. Lee, X. Tan and S. Trimi, "Current Practices of Leading e-Government Countries", Communications of the ACM 48, 99-104(2005).

6. N.J. Lightner, "Evaluating E-commerce functionality with a focus on customer service", Communication of the ACM 47,88-92 (2004).

7. Z. Yang, S. Cai, Z. Zhou and N. Zhou, "Development and validation of an instrument to measure user perceived service quality of information presenting Web portals", Information \& Management ,42,575-589 (2005).

8. Social welfare act 1982. 